\title{
Antibiotic Sensitivity Pattern and Prevalence of Methicillin Resistant Staphylococcus aureus (MRSA) at Tertiary Care Hospital
}

\author{
Jaydev Pandya ${ }^{1}$ and Mitesh Kamothi ${ }^{2 *}$ \\ ${ }^{1}$ GMERS Medical College, Junagadh, Gujarat, India \\ ${ }^{2}$ (Microbiology), GMERS Medical College, Gotri, Vadodara, Gujarat, India \\ *Corresponding author
}

\section{A B S T R A C T}

\begin{tabular}{|l|}
\hline Key w or d s \\
MRSA, \\
$\begin{array}{l}\text { Staphylococcus } \\
\text { aureus, Antimicrobial } \\
\text { resistance. }\end{array}$ \\
\hline Article Info \\
\hline $\begin{array}{l}\text { Accepted: } \\
\text { 07 September } 2017 \\
\text { Available Online: } \\
\text { 10 November } 2017\end{array}$ \\
\hline
\end{tabular}

The present study was carried out to detect the sensitivity pattern and prevalence of Methicillin Resistant Staphylococcus aureus (MRSA) at tertiary care hospital, Surendranagar. Total 1776 Clinical specimens were studied. All the isolates were identified by standard microbiological procedures like gram staining, colony morphology on solid culture media and biochemical reactions. Antibiotic sensitivity testing was done for all isolates by modified Kirby Bauer disk diffusion method. Total 194 Staphylococcus aureus were tested for MRSA by Cefoxitin disc diffusion test. Among 194 Staphylococcus aureus only 69 were positive for MRSA. Overall prevalence rate for MRSA isolates was $35.56 \%$. Maximum occurrence of MRSA was in Medicine ward (45.31\%), Surgery ward $(21.87 \%)$ and Orthopedic ward $(15.62 \%)$. MRSA were maximum from Pus $(43.75 \%)$ followed by Urine (26.56\%), Swab (12.5\%), Sputum (10.93\%), Blood (3.12\%) and Body fluid $(1.56 \%)$. MRSA were most sensitive to Vancomycin (100\%) followed by Linezolid (93\%) and Doxycycline (79\%), and least sensitive to Clarithromycin (20\%) followed by Roxythromycin (28\%) and Erythromycin (34\%). Prevalence of MRSA in our study is $35.56 \%$, which are multidrug resistance though Vancomycin, Linezolid and Doxycyclin are still effective treatment option.

\section{Introduction}

The antibiotics used to treat people today are typically derivatives of natural substances secreted by bacteria and fungi. Hospitals have become a breeding ground for antibiotic resistant bacteria. These bacteria proliferate in an environment filled with sick people who have poor immune systems and where antibiotics have eliminated competing bacteria that are not resistant. Antibiotics have been critical in the fight against infectious disease caused pathogenic microorganisms. Antimicrobial chemotherapy has been a leading cause for the rise of average life expectancy in the $20^{\text {th }}$ Century. But, pathogenic microorganisms that have become resistant to antibiotic drug therapy are an increasing public health problem. One part of the problem is that pathogenic bacteria that cause infections are remarkably resilient and have developed several ways to resist antibiotics. Another part of the problem is due to increasing use, and misuse, of existing antibiotics in human, veterinary medicine and in agriculture. Nowadays, about $70-75 \%$ percent of the bacteria that cause infections in hospitals are resistant to at least one of the 
drugs most commonly used for treatment. Some pathogenic organisms are resistant to all approved antibiotics and can only are treated with experimental and potentially toxic drugs.

Antibiotic means "against life", and effective antibiotics can inhibit microbial growth (bacteriostatic) or kill the microbe (bacteriocidal). The majority of antibiotics are natural products because they were isolated from bacteria or fungi. The next largest class of antibiotics is semi-synthetic-natural products that have been slightly altered, by addition or subtraction of substituents for example, to improve efficacy or lower toxicity. Only about $10 \%$ of the antibiotics in clinical use today are completely synthetic, and most of these compounds were designed to inhibit a process that is unique and essential to the bacterium. In the more than half century since penicillin entered the clinical realm, the pharmaceutical industry has developed more than 150 antibiotics, with over 50 additional analogues of the 3rd generation cephalosporins and quinolones since they were first introduced in the early 1980 's ${ }^{(1,2)}$. These antibiotics target a variety of sites within a bacterial cell including the inhibition of cell wall biosynthesis, protein synthesis, and nucleic acid function. Staphylococcus aureus bacteria have a longterm history as a cause of human disease all around the world. Previously invasive $S$. aureus infections were almost fatal. The introduction of penicillin greatly improved prognosis for these serious cases; but, resistant strains of bacteria appeared within a few years. In 1960, methicillin was introduced as an alternative treatment for penicillin-resistant bacteria, but within six months, a hospital in the United Kingdom reported methicillin resistant $S$. aureus (MRSA). Since then, MRSA has become a problem worldwide. The epidemiology of MRSA became more complex when a genetically novel strain of communityassociated MRSA (CA-MRSA) was reported in 1993. Previously, MRSA was only seen in people who had frequent contact with health care facilities. People who had long or repeated hospital stays were the most likely to develop the infection. The first strain of CAMRSA was discovered in populations living in Western Australia who had no previous contact with the hospitals. Methicillin resistance in $S$. aureus is due to the presence of the mecA gene. The mecA gene encodes the penicillin-binding protein (PBP) $2 \mathrm{a}$ (or PBP2'). PBPs are membrane-bound enzymes that catalyze the transpeptide reaction that is necessary for the cross-linkage of the peptidoglycan chains that are a major component of the staphylococcal cell wall. $\beta$ lactam antibiotics normally bind to penicillinbinding protein in the cell wall, causing a disruption of the synthesis of peptidoglycan layer and resulting in cell death. However, the penicillin-binding protein has a low affinity for $\beta$ - lactam antibiotics like methicillin, so even in the presence of these antibiotics, peptidoglycan synthesis and normal cell wall growth will continue uninterrupted.

One of the major challenges in MRSA investigations is differentiating between hospital and community cases. Hospital cases are known as "hospital associated," "hospital acquired," or "HA". Community cases are known as "community associated," "community acquired," "community onset," "community derived," or "CA." The CDC has defined a community-associated MRSA (CAMRSA) case as a patient with a MRSA infection and no history of the surgery, hospitalization, residence in a long-term care facility, or dialysis within one year prior to infection; presence of a percutaneous device or indwelling catheter; hospitalization $>48$ hours before the culture; or history of previous MRSA infection or colonization. A case of HAMRSA can be defined as any 
MRSA infection that does not qualify as CAMRSA. Prevalence of MRSA was reported in Taiwan, Japan and Hongkong $(>60 \%)$, England (27.5\%) and Africa (5\% to $45 \%)$, Iceland $(0.5 \%)$ and Greece (44\%), Pakistan (33.88\%) and Egypt (43.80\%). In India, different authors had reported a prevalence of MRSA from $29.10 \%$ to $54.90 \%$.

Laboratory detection techniques: Strains that possess mecA gene are heterogeneous or homogeneous in expression of resistance. The heterogeneous expression occasionally results in minimal inhibitory concentrations that appear to be borderline and consequently the isolates may be interpreted as susceptible. The presence of both resistant and nonresistant bacteria, can make it difficult to detect methicillin resistance. Their detection using methicillin and oxacillin is aided by following changes: 1. Neutral $\mathrm{pH}, 2$. Incubation temperature of $33^{\circ} \mathrm{C}-35^{\circ} \mathrm{C}, 3$. Mueller-Hinton agar or broth infused with $2 \%-4 \% \mathrm{NaCl}$, and 4. 24-hour incubation time. Several selective media have been used for screening MRSA, such as mannitol salt agar with oxacillin, Oxacillin blood agar and CHROM agar.

Treatments for MRSA infection may vary depending upon the site of infection. The most important first step to the treatment is the incision and drainage of an abscess or removal of an infected medical device. Antibiotic selection is also useful to successful treatment. According to B.A. Cuhna, five antimicrobial agents demonstrate high degrees of effectiveness in vivo against MRSA: quinupristin/dalfopristin, minocycline, daptomycin, linezolid, and vancomycin. All of these are available in intravenous form, but minocyline and linezolid are both available in oral form. Serious, invasive infections are treated with intravenous Vancomycin. It is also recommends TMP-SMX or doxycyline as first-line agents and clindamycin and linezolid as second-line agents, noting that the secondline agents have high levels of inducible resistance.

\section{Materials and Methods}

The present study was conducted at the Department of Microbiology of C. U. Shah medical college and hospital, Surendranagar, Gujarat. Total 1776 Clinical specimens were included in the study. The isolates were identified as per standard microbiological procedures like gram staining, colony morphology on solid culture media\& biochemical reactions. Cefoxitin disc diffusion test: All isolated Staphylococcus aureus were screened for MRSA by CLSI recommended disk diffusion test. Mueller Hinton agar plates inoculated with standardized inoculum $(0.5 \mathrm{Mc}$ Farland standard) of the isolate. A $30 \mu \mathrm{g}$ cefoxitin disc was placed and plates were incubated at $35^{\circ}$ $\mathrm{C}$ for $18 \mathrm{~h}$. Zone diameters are measured in reflected light. An inhibition zone diameter of $\leq 21 \mathrm{~mm}$ was reported as methicillin resistant and $\geq 22 \mathrm{~mm}$ was considered as methicillin susceptible. Quality control strains like Methicillin sensitive $S$. aureus (MSSA) ATCC 25923 and methicillin resistant $S$. aureus (MRSA) ATCC 43300 were used.

\section{Results and Discussion}

Total 1776 clinical specimens were received in the Department of Microbiology of C. U. Shah Medical College and Hospital, Surendranagar, out of 1776 clinical specimens, 797 did not shown any growth while 979 had shown growth of various microorganisms.

Maximum number of specimens were Urine (641) followed by Sputum (449), Pus (327), Swab (156), Blood (75), Body fluids (64), Stool (52), CSF (12). The maximum number 
of isolates were isolated from Urine (441) followed by Sputum (236), Pus (172), Swab (71), Blood (26), Body fluids (19) and Stool (14). The most common bacterial isolates were Escherichia coli (434) followed by Klebsiella spp. (212), Staphylococcus aureus (194), Pseudomonas aeruginosa (61), Coagulase Negative Staphylococci (33), Enterococci (25), Proteus mirabilis (11) and Acinetobacter spp. (9).

From total 1776 clinical specimens 194 Staphylococcus aureus were isolated. Among 194 Staphylococcus aureus only 69 were positive for MRSA, so overall prevalence rate for MRSA isolates was $35.56 \%$. As shown in the table 1, maximum occurrence of MRSA was in Medicine ward (45.31\%), Surgery ward $(21.87 \%)$ and Orthopaedic ward (15.62\%). Table 2 shows isolation of MRSA were maximum from Pus $(43.75 \%)$ followed by Urine (26.56\%), Swab (12.5\%), Sputum $(10.93 \%)$, Blood $(3.12 \%)$ and Body fluid $(1.56 \%)$. As shown in the table 3, MRSA were most sensitive to Vancomycin (100\%) followed by Linezolid (93\%) and Doxycycline (79\%), and least sensitive to Clarithromycin (20\%) followed by
Roxythromycin (28\%) and Erythromycin $(34 \%)$.

The microbial pathogens, as well as their antibiotic sensitivity patterns may change from time to time and place to place. The discovery of antibiotics revolutionized the management of infectious diseases. Irrational and inappropriate use of antimicrobials medicines provides favorable conditions for resistant microorganisms to emerge, spread and persist and is by far the biggest driver of drug resistance worldwide. Drug resistance threatens to erase gains made in disease treatment and control in developing countries. No action today means no cure tomorrow. Infections caused by resistant microorganisms fail to respond to the standard treatment therapy which results in prolonged illness and higher risk of death. When infections become resistant to first line drugs, more expensive drugs must be used. The longer duration of illness and treatment, increases hospital costs and the financial burden to families and societies. Hospital antibiograms are commonly used to help guide empiric antimicrobial treatment and are an important component of detecting and monitoring trends in antimicrobial resistance.

Table.1 Ward wise distribution of MRSA

\begin{tabular}{|l|c|c|}
\hline \multicolumn{1}{|c|}{ Ward } & Number & \% \\
\hline Medicine & 29 & 45.31 \\
\hline Surgery & 14 & 21.87 \\
\hline Orthopedic & 10 & 15.62 \\
\hline ENT & 7 & 10.93 \\
\hline Obstetrics \& Gynecology & 3 & 4.68 \\
\hline Pediatric & 1 & 1.56 \\
\hline Total & 64 & 100 \\
\hline
\end{tabular}


Table.2 Specimen wise distribution of MRSA

\begin{tabular}{|l|c|c|}
\hline \multicolumn{1}{|c|}{ Specimen } & Number & \% \\
\hline Pus & 28 & 43.75 \\
\hline Urine & 17 & 26.56 \\
\hline Swab & 8 & 12.5 \\
\hline Sputum & 7 & 10.93 \\
\hline Blood & 2 & 3.12 \\
\hline Bodyfluid & 1 & 1.56 \\
\hline Total & 64 & 100 \\
\hline
\end{tabular}

Table.3 Percentage of antibiotic sensitivity of MRSA

\begin{tabular}{|l|c|}
\hline \multicolumn{1}{|c|}{ Antibiotic } & MRSA \\
\hline Vancomycin & 100 \\
\hline Linezolid & 93 \\
\hline Doxycycline & 79 \\
\hline Teicoplanin & 78 \\
\hline Tetracycline & 64 \\
\hline Clindamycin & 60 \\
\hline Co-trimoxazole & 39 \\
\hline Ciprofloxacin & 38 \\
\hline Gentamycin & 36 \\
\hline Erythromycin & 34 \\
\hline Roxythromycin & 28 \\
\hline Clarithromycin & 20 \\
\hline
\end{tabular}

Table.4 Prevalence of MRSA

\begin{tabular}{|l|c|}
\hline \multicolumn{1}{|c|}{ Author } & Prevalence \\
\hline Bustamante et al., (2011 - England) & $27.5 \%$ \\
\hline Boucher et al., (2002 - Greece) & $44 \%$ \\
\hline Hafeez et al., (2004 - Pakistan) & $33.88 \%$ \\
\hline Al-baidani et al., (2011 - Egypt) & $48.30 \%$ \\
\hline Prakash et al., (2007-Tamilnadu) & $35 \%$ \\
\hline Khadri and Alzohairy (2008-Anantapur) & $54.9 \%$ \\
\hline Tiwari et al., (2008-Varanasi) & $38.44 \%$ \\
\hline Murugan et al., (2008-Coimbatore) & $42.86 \%$ \\
\hline Arora and Arora (2010-Punjab) & $46 \%$ \\
\hline Pai et al., (2010-Karnataka) & $29.10 \%$ \\
\hline Tsering et al., (2011-Sikkim) & $38.14 \%$ \\
\hline Shazia Parveen et al., (2011-Andhra Pradesh) & $48 \%$ \\
\hline Present Study & $\mathbf{3 5 . 5 6 \%}$ \\
\hline
\end{tabular}


Table.5 Percentage of antibiotic sensitivity of MRSA in different studies

\begin{tabular}{|c|c|c|c|c|c|c|c|c|}
\hline $\begin{array}{l}\text { Antibiotics } \rightarrow \\
\text { Authors } \\
\downarrow\end{array}$ & 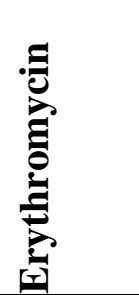 & 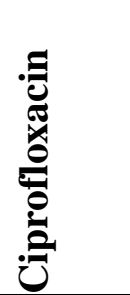 & 苞 & 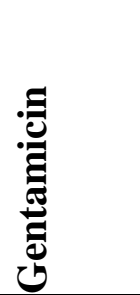 & 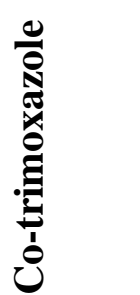 & 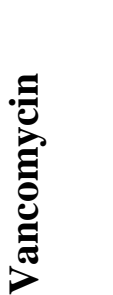 & 起 & 竭 \\
\hline $\begin{array}{l}\text { Khadri et al., } \\
\text { (2008-Anantapur) }\end{array}$ & 17 & 60 & 39 & 27 & 18 & 100 & - & - \\
\hline $\begin{array}{l}\text { Tiwari et al., } \\
\text { (2008-Varanasi) }\end{array}$ & 31.23 & 24.25 & 23.9 & 44.11 & 4.32 & 99.67 & - & - \\
\hline $\begin{array}{l}\text { Saikia et al., } \\
\text { (2009-Assam) }\end{array}$ & 18.75 & 12.5 & - & 12.5 & 3.12 & - & - & 43.75 \\
\hline $\begin{array}{l}\text { Prakash } \text { et al., } \\
\text { (2007-Tamilnadu) }\end{array}$ & 80.9 & 71.42 & - & - & - & 90.4 & - & - \\
\hline $\begin{array}{l}\text { Murugan } \text { et } \\
\text { al.,(2008- } \\
\text { Coimbatore) }\end{array}$ & 39.92 & 51.92 & - & 35.89 & 17.22 & 100 & 87.1 & - \\
\hline $\begin{array}{l}\text { Arora and Arora } \\
\text { (2010-Punjab) }\end{array}$ & 38.3 & 32.2 & - & 27.8 & - & 100 & 98.3 & - \\
\hline $\begin{array}{l}\text { Hafeez et al., } \\
\text { (2004-Pakistan) }\end{array}$ & 5.25 & 3.7 & - & 24.07 & 14.81 & 100 & 20.37 & - \\
\hline Present study & 34 & 38 & 64 & 36 & 39 & 100 & 93 & 60 \\
\hline
\end{tabular}

In the present study the most common bacterial isolates from various clinical specimens like Urine, Sputum, Pus, Swab etc. were Escherichia coli (434) followed by Klebsiella spp. (212), Staphylococcus aureus (194), Pseudomonas aeruginosa (61), Coagulase Negative Staphylococci (33), Enterococci (25), Proteus mirabilis (11) and Acinetobacter spp. (9). Staphylococcus aureus is the leading cause of gram positive bacterial infections and produces a wide spectrum of diseases, ranging from minor skin infections to fatal necrotizing pneumonia. Although $S$. aureus infections were historically treatable with common antibiotics, emergence of drug-resistant organisms is now a major concern. Methicillin-resistant Staphylococcus aureus (MRSA) was endemic in hospitals by the late 1960s, but it appeared rapidly and unexpectedly in communities in the 1990s and is now prevalent worldwide. Table 4 shows in present study, the prevalence rate of MRSA was $35.56 \%$ which is higher than the study of Pai et al., (2010) (29.10\%) and almost similar to the study of Prakash et al., (2007) (35\%), while study of Khadri and Alzohairy (2010) (54.90\%) showed much higher prevalence rates and all other study showed prevalence rate $(38.14 \%$ - $48 \%)$. As shown in table 5. In present study, MRSA was found most sensitive to Vancomycin $(100 \%)$ followed by Linezolid (93\%) and Tetracycline (64\%). In our study, Vancomycin showed $100 \%$ sensitivity to all the MRSA isolates similar results were found by Khadri and Alzohairy (2010), Murugan et al., (2008), Arora and Arora (2010) and Hafeez et al., (2004) while study of Tiwari et al., (2008) and Prakash et al., (2007) showed $99.67 \%$ and $90.4 \%$ sensitivity respectively. In present study, Tetracycline (64\%) showed 
higher sensitivity than the study of Khadri and Alzohairy (2010) (39\%) and Tiwari et al., (2008) (23.9\%). In present study, Ciprofloxacin (38\%) showed reduced sensitivity than the study of Murugan et al., (2008) (51.92\%), Khadri and Alzohairy (2010) (60\%) and Prakash et al., (2007) $(71.42 \%)$. Linezolid showed high sensitivity in all the above study. According to this study, Vancomycin is the only antibiotic which showed $100 \%$ sensitivity. Vancomycin remains the first choice of treatment for MRSA so Vancomycin use should be limited to those cases where there are definitely needed to preserve its value. However, due to increasing of Vancomycin MICs for MRSA, regular monitoring of Vancomycin sensitivity and routine testing of new glycopeptides must be carried out. To improve the outcome of serious infections and to overcome these difficulties monitoring of resistance patterns in the hospital is required.

The prevalence of methicillin resistant Staphylococcus aureus was $35.56 \%$ in the institution. MRSA strains were resistant to a number of antibiotics, but uniformly susceptible to vancomycin and linezolid.

\section{References}

Al-baidani, A. H., El-shouny, W. A., Shawa, T. M. 2011."Antibiotic Susceptibility of Methicillin Resistant Staphylococcus aureus in three hospitals at Hodeidah city, Yemen"Global J Pharmacol, vol. 5, no. 2, pp. 106-11.

Arora, S., Arora, U. 2010. "Prevalence of Methicillin-resistant Staphylococcus aureus (MRSA) in a Tertiary Care Hospital in Northern India" $J$ Lab Physicians, vol. 2, no. 2, pp.78-81.

Boucher, H. W., Ralph Corey, G. 2008. "Epidemiology of Methicillin-Resistant Staphylococcus aureus" Clinico Infectio Diseases, vol. 46, pp. 344-9.
Buck, J. M., Como-Sabetti, K., Harriman, K. H., Danila, R.N. 2005. "CommunityAssociated methicillin-resistant Staphylococcus aureus, Minnesot", Emergo Infectio Diseases, vol. 11, no. 10 , pp. 1532-8.

Bustamante, N. D. 2011 “ MRSA - A global threat" UT South Western medical school pp. 1- 19.

Cunha, B. A., 2005."Methicillin-resistant Staphylococcus aureus: Clinical manifestations and antimicrobial therapy" Clinical Microbiology and Infection, vol. 11, no. 4, pp. 33-42.

Hafeez, R., Chughtai, A. S., Aslam, M. 2004. "Prevalence and Antimicrobial Susceptibility of Methicillin Resistant Staphylococcus aureus (MRSA)" I J Patholvol. 2, no. 1, pp. 10-15.

Khadri, H., Alzohairy, M. 2010. "Prevalence and antibiotic susceptibility pattern of methicillin-resistant and coagulasenegative staphylococci in a tertiary care hospital in India" I $J$ Medicine and Medical Sciences, vol. 2, no. 4, pp. 11620.

Lee, V. J., Miller, G. H., Yagisawa, M. 1999. "What's new in the antibiotic pipeline", Curr Opin Microbiol, vol.2, pp. 475-82.

Lowy, F. D. 2003. " Antimicrobial resistance: the example of Staphylococcus aureus", J Clinico Investigo, vol.111, no. 9, pp. 1265-73.

Mathur, M., Taklikar, S., Sarkar, S., D’souza, D. 2007. "A Four-year Audit of MRSA in a Tertiary Care Hospital" Bombay Hospital J, pp. 579-83.

Murugan, S., Mani, K. R., Umadevi, P. 2008. "Prevalence of Methicillin Resistant Staphylococcus aureus among Diabetes Patients with Foot Ulcers and their Antimicrobial Susceptibility Pattern" $J$ Clinical and Diagnostic Research, vol. 2, pp. 979-84 
Neu, H. C. 1992. "The crisis of antibiotic resistance", Science, vol. 257, pp.106473.

Padmanabhan, R. A., Fraser, T. G. 2005. "The emergence of methicillin-resistant Staphylococcus aureus in the community" Cleveland Clinic J Medicine. Vol. 72, no. 3, pp. 235-41.

Pai, V., Rao, V. I., Rao, S. P. 2010. "Prevalence and Antimicrobial Susceptibility Pattern of Methicillinresistant Staphylococcus aureus [MRSA] Isolates at a Tertiary Care Hospital in Mangalore, South India" $J$ Lab Physicians, vol. 2, no. 2, pp. 82-4.

Prakash, M., Rajasekar, K., Karmegam, N. 2007."Prevalence of Methicillin Resistant Staphylococcus aureus in Clinical Samples Collected from Kanchipuram Town, Tamil Nadu, South India" J Applied Sciences Research, vol. 3 , no. 12 , pp. 1705- 9 .

Saikia, L., Nath, R., Choudhury, B., Sarkar, M. 2009. "Prevalence and antimicrobial susceptibility pattern of methicillinresistant Staphylococcus aureus in Assam" Indian J Crit Care Med. Vol. 13, no. 3, pp. 156-8.

Sedgwick, P. E., Dexter, W. W., Smith, C. T. 2007. "Bacterial Dermatoses in Sports" Clinics in Sports Medicine. vol. 26, pp. 383-96.

Shazia Parveen, S., Jyothsna, K. 2011."Methicillin Resistance among Isolates of Staphylococcus aureus: Antibiotic Sensitivity Pattern and Phage Typing" J Biological Research, vol. 2, no. 4, pp: 57-61.

Tiwari, H. K., Sapkota, D., Sen, M. R. 2008. "High prevalence of multidrug-resistant MRSA in a tertiary care hospital of northern India" Infect Drug Resist, vol. 1, pp. 57-61.

Tsering, D. C., Pal, R., Kar, S. 2011. "Methicillin-Resistant Staphylococcus aureus: Prevalence and Current Susceptibility Pattern in Sikkim" J Glob Infect Dis, vol. 3, no. 1, pp. 9-13.

\section{How to cite this article:}

Jaydev Pandya and Mitesh Kamothi. 2017. Antibiotic Sensitivity Pattern and Prevalence of Methicillin Resistant Staphylococcus aureus (MRSA) at Tertiary Care Hospital. Int.J.Curr.Microbiol.App.Sci. 6(11): 423-430. doi: https://doi.org/10.20546/ijcmas.2017.611.049 